\title{
SUBJECTS AND OBJECTS OF ENVIRONMENTAL LEGAL RELATIONS
}

\author{
Anatoly Ya. Ryzhenkov \\ B.B. Gorodovikov Kalmyk State University, Elista, Russian Federation
}

\begin{abstract}
Introduction: the need to study the category "legal relationship" is generally recognized in the theory of law and state, as well as in all sectoral sciences. However, if the category "legal relationship" is sufficiently developed in relation to the "traditional" branches of law, then this issue remains relevant and new in relation to a fairly young branch of environmental law. The purpose of the research: to show the dynamics of development of modern doctrinal discussions on key issues of the theory of environmental law, namely, the categories of the subject and object of environmental legal relations. Objectives: to show the position of major Russian and foreign scientific schools on the theory of ecological legal relations; to identify the main scientific doctrine concerning the understanding of the subject of environmental legal relations; to consider the existing point of view on the category of the object of ecological relations. Methods: dialectical, system, logical, analysis, synthesis. Results: the dynamics of the doctrinal development of the concept of the subject and object of environmental relationship is investigated; the points of view of the leading environmental law schools of the CIS countries on the existing and prospective subjects of ecological legal relations are considered; the views of modern scholars regarding the recognition of climate as well as the person to be the subject of environmental legal relations are assessed within the category "the object of ecological relationship". Conclusions: the paper argues that in the theory of environmental law, the categories "subject" and "object" of environmental legal relations are the most discussed today. The emergence of a new subject of environmental legal relations - "future generations", mentioned in the legislation, seems to be justified. The paper presents a number of arguments in support of the existing proposals to expand the traditional list of the objects of environmental legal relations, with the addition of quasi-natural objects, agricultural ecosystem, climate, and many others.
\end{abstract}

Key words: legal relationship, subject, object, climate, environmental law, man, nature, future generations.

Citation. Ryzhenkov A.Ya. Subjects and Objects of Environmental Legal Relations. Legal Concept $=$ Pravovaya paradigma, 2020, vol. 19, no. 4, pp. 100-109. (in Russian). DOI: https://doi.org/10.15688/lc.jvolsu.2020.4.13

\section{СУБЪЕКТЫ И ОБЪЕКТЫ ЭКОЛОГИЧЕСКИХ ПРАВООТНОШЕНИЙ}

\author{
Анатолий Яковлевич Рыженков \\ Калмыцкий государственный университет им. Б.Б. Городовикова, г. Элиста, Российская Федерация
}

\begin{abstract}
Введение: необходимость изучения категории «правоотношение» является общепризнанной в теории права и государства, а также во всех отраслевых науках. Однако если применительно к «традиционным» отраслям права категория «правоотношение» является достаточно проработанной, то в отношении достаточно молодой отрасли экологического права данный вопрос сохраняет свою актуальность и новизну. Цель исследования: показать динамику развития современных доктринальных дискуссий по ключевым проблемам теории экологического права, а именно по категориям субъект и объект экологического правоотношения. Задачи: показать позицию основных российских и зарубежных научных школ по вопросам теории экологического правоотношения; выявить основные научные доктрины, касающиеся понимания субъекта экологического правоотношения; рассмотреть сложившиеся точки зрения на категорию объект экологического правоотношения. Методы: диалектический, системный, логический, анализ, синтез. Результаты: исследована динамика развития доктринальной концепции субъекта и объекта экологического правоотношения, рассмотрены точки зрения ведущих эколого-правовых научных школ стран СНГ о существующих и
\end{abstract}


перспективных субъектах экологических правоотношений, в рамках категории «объект экологического правоотношения» дана оценка взглядам современных ученых относительно признания климата, а также человека объектом экологического правоотношения. Выводы: в статье аргументируется вывод о том, что в теории экологического права наибольшие дискуссии сегодня вызывают категории «субъект» и «объект» экологического правоотношения. Представляется обоснованным появление нового субъекта экологических правоотношений - «будущих поколений», упоминаемых в законодательстве. В статье высказывается ряд аргументов в поддержку существующих предложений по расширению традиционного перечня объектов экологических правоотношений с добавлением в него квазиприродных объектов, аграрной экосистемы, климата и многих других.

Ключевые слова: правоотношение, субъект, объект, климат, экологическое право, человек, природа, будущие поколения.

Цитирование. Рыженков А. Я. Субъекты и объекты экологических правоотношений // Legal Concept = Правовая парадигма. - 2020. - Т. 19, № 4. - C. 100-109. - DOI: https://doi.org/10.15688/lc.jvolsu.2020.4.13

\section{Введение}

Необходимость изучения категории «правоотношение» является общепризнанной в теории права и государства, а также во всех отраслевых науках. Однако если применительно к «традиционным» отраслям права категория «правоотношение» является достаточно проработанной, то в отношении достаточно молодой отрасли экологического права данный вопрос сохраняет свою актуальность и новизну. Специфику таким дискуссиям придает то, что в рамках науки экологического права существует два подхода к пониманию его предмета. Сторонники широкого подхода полагают, что нормы экологического права регулируют природоресурсные (по использованию вод, лесов, недр и иных природных ресурсов) и природоохранные (по охране и восстановлению надлежащего качества природных объектов и комплексов) отношения [5, c. 37-38]. Представители узкого подхода отмечают, что земельное, водное, лесное, горное, фаунистическое право находятся на разных стадиях оформления в качестве самостоятельных отраслей в системе российского права, а наименование «природоресурсное право» (как их общее название) означает лишь признание родственных целей и методов правового регулирования соответствующих отношений (как частное право - это общее название гражданского, семейного и жилищного права) [2, с. 91-97].

Соответственно, экологическое право не регулирует отношения собственности или иных (вещных и обязательственных) прав на природные ресурсы и делает основной акцент лишь на природоохранных вопросах. При этом сторонники данной концепции не отрицают наличие тесной взаимосвязи между использованием и охраной природных ресурсов, однако объясняют ее посредством концепции межотраслевых связей, детально разработанной, например, в науке гражданского права М.Ю. Челышевым [24].

Исходя из указанных обстоятельств, понятие и содержание экологических правоотношений будет сильно отличаться в зависимости от того, какой из названных позиций придерживается конкретный исследователь. Попробуем рассмотреть теорию экологических правоотношений в узком смысле.

При таком подходе экологические правоотношения - это урегулированные нормами экологического и иных отраслей права общественные отношения в сфере взаимодействия природы и общества по поводу исполнения и соблюдения природопользователями экологических требований, нормативов и технических регламентов, создания особо охраняемых природных территорий и охраны отдельных природных объектов, а также использования гражданами мер по защите своего права наблагоприятную окружающую среду.

\section{Субъекты \\ экологических правоотношений}

Правовые отношения «всегда предполагают наличие субъектов права, общественнопроизводственные отношения которых опосредуются как правовые. Субъектом права может быть только человек или человеческий коллектив - индивидуальный или коллек- 
тивный хозяйствующий субъект, но не имущество, не какая-либо цель, и не любое имя или понятие» [8, с. 295-296].

Единой общепризнанной классификации субъектов экологических правоотношений в настоящий момент не разработано. В связи с этим одни авторы (А.И. Федор) предлагают выделять по критерию содержания прав и обязанностей четыре группы таких субъектов: природопользователи, органы исполнительной (в том числе специально уполномоченные органы) и представительной власти, общественные экологические организации, органы судебно-прокурорского надзора [22, с. 15-16]. Положительным в этой классификации является то, что учтены все три ветви власти, действительно по-разному участвующие в экологических правоотношениях (поскольку нормотворчество или отправление правосудия это тоже формы участия). Кроме того, эта классификация позволяет отобразить все уровни публичных субъектов экологических правоотношений (федеральные, региональные и муниципальные органы).

Однако при таком подходе не учитываются граждане и иные (необщественные) объединения, не являющиеся природопользователями.

Другие авторы выделяют в качестве субъектов: государство; государственные органы; юридические лица (в том числе иностранные и международные); физические лица (в том числе иностранцы и лица без гражданства); иностранные государства [17, с. 51]. Однако в данном случае не совсем ясен критерий, по которому разделяются «государство» и «государственные органы», поскольку функции государства как раз и реализуются посредством деятельности его органов. Кроме того, в этой классификации нет органов местного самоуправления (которые в силу ст. 12 Конституции РФ не входят в систему органов государственной власти). Что же касается иностранных государств, то они могут выступать субъектами экологических правоотношений на территории России только в порядке и объеме, предусмотренном международными договорами. Наконец, отмечу, что юридические лица указаны авторами все вместе (и коммерческие организации, и общественные объединения), однако их правосубъ- ектность не совпадает. Примечательно, что последняя позиция о выделении в качестве отдельных субъектов экологических правоотношений иностранных государств является довольно распространенной и в научных школах за пределами России. Например, их выделяют в белорусской эколого-правовой научной школе $[25$, с. 56$]$. При этом, если в Беларуси ст. 6 Закона Республики Беларусь «Об охране окружающей среды» от 26 ноября 1992 г. № 1982-XII (ред. от 18.06.2019) иностранные государства прямо обозначены, то в его российском аналоге (Федеральном законе «Об охране окружающей среды» от 10 января 2002 г. № 7-Ф3) таких упоминаний нет. В связи с этим включение иностранных государств в перечень субъектов экологических правоотношений можно рассматривать как предложение восполнить пробел в праве.

А.И. Мирошниченко предлагает считать участниками экологических правоотношений «человека, органы государственной власти и общественного самоуправления, общественные, международные, и межправительственные организации» [13, с. 13]. В данной классификации, однако, не совсем понятны отличия между «общественными» организациями и органами «общественного самоуправления», причем автор не упоминает органы местного самоуправления. Представляется, что в числе субъектов экологических правоотношений следует указать граждан, юридических лиц (коммерческих и некоммерческих, включая иностранных), Российскую Федерацию, субъектов РФ и муниципальные образования. Кроме того, следует обратить внимание на два обстоятельства. Во-первых, в некоторых (общерегулятивных) правоотношениях граждане участвуют вне зависимости от возраста и состояния дееспособности. Речь в данном случае идет об отношениях в сфере общего природопользования (право дышать чистым воздухом, употреблять безопасную для здоровья питьевую воду и т. д.). Во-вторых, характерной чертой субъектного состава экологических правоотношений является практически постоянное участие в них государства (Российской Федерации, субъектов РФ), реже - муниципальных образований.

Отдельным дискуссионным субъектом экологических правоотношений являются «бу- 
дущие поколения», о которых идет речь во множестве международных актов. Об ответственности перед «нынешним и будущими поколениями» упоминается в преамбуле Конституции РФ. Будущие поколения в разных контекстах упоминаются в ст. 1 Градостроительного кодекса РФ (в рамках принципа устойчивого развития территории), Федеральном законе «Об охране окружающей среды» (преамбула и ст. 63.1), ст. 35 Закона РФ «О недрах», ст. 3 Федерального закона «Об охране атмосферного воздуха» и ряде других федеральных экологических законодательных актов. Об этом также было сказано и в Послании Президента РФ Федеральному Собранию от 20 февраля 2019 г.: «Мы должны передать будущим поколениям экологически благополучную страну, сохранить природный потенциал и заповедный фонд России» [15]. Однако никаких четких критериев и процедур по реализации прав данной разновидности субъектов экологическое законодательство пока не предусматривает.

\section{Объект \\ экологических правоотношений}

В советской юридической науке были обоснованы две концепции объекта правоотношений - монистическая и плюралистическая. В рамках первой выделялись две теории объекта (вещная и поведенческая).

Монистическая концепция считала объектом правоотношения только вещи как предметы материального мира, которые могут находиться в твердом, жидком, газообразном или ином физическом состоянии, а также результаты интеллектуальной деятельности. Поведенческая теория «признавала объектом правоотношения действия субъектов, в то время как материальные и нематериальные блага являлись целью, ради которой лица вступали в правоотношения» [23, с. 106-108].

В рамках плюралистической концепции указывалось на то, что не может быть одного (единственного) объекта правоотношения, их существует множество и они носят разнообразный характер. В зависимости от вида гражданского правоотношения «в качестве его объекта могут выступать как материальные и духовные блага, получение и использо- вание которых составляет интерес управомоченной стороны, так и действия по их приобретению» [21, с. 406]. Разграничение материальных благ и действий как объектов экологических правоотношений в экологическом праве пока не разработано, и большинство авторов считает объектом экологических правоотношений то благо, на которое направлено поведение его участников. Таким благом являются компоненты природной среды, природные объекты и комплексы. Между тем исследование действий в рамках плюралистической концепции представляется весьма важным, поскольку в экологическом праве интересы сторон могут быть направлены исключительно на совершение действий (требования о получении экологической информации), лишь опосредовано относящихся к конкретным природным объектам. Именно в этом смысле понимают категорию «объект» представители харьковской научной школы экологического права (Украина), различая в качестве объектов экологических правоотношений природные объекты, вещи, неимущественные блага, а также результаты действий [26, с. 14].

Не менее интересно и предложение юристов-экологов из Республики Казахстан, полагающих, что «объектом экологического правоотношения является юридически упорядоченное взаимодействие субъектов данного отношения, складывающееся в процессе реализации экологического права, законного экологического интереса либо экологической обязанности» [3, с. 61]. Думается, что дальнейшая разработка правовой категории «объект экологического правоотношения» должна включать изучение не только объектов материального мира (природных объектов), но и действий субъектов, а также нематериальных благ. При рассмотрении объектов экологических правоотношений весьма важным представляется решение вопроса об отграничении данной категории от объектов, регулируемых нормами иной отраслевой принадлежности.

Так, представители белорусской правовой науки отмечают, что отнесение белорусским законодательством о животном мире диких животных, находящихся в неволе, к объектам экологических правоотношений (животному миру) некорректно, равно как и включение дендрологических парков и ботаничес- 
ких садов в состав ООПТ. Совсем другое дело - это включение рядом международных актов в разряд объектов экологических правоотношений «биологического разнообразия» $[25$, с. 58$]$. В свою очередь, российские ученые отмечают, что «следует как минимум выделить в качестве особого объекта правового регулирования биологические ресурсы, биоразнообразие, экосистемы, безопасность человека, глобальные экологические услуги» [4, c. 128-129]. В данном случае следует заметить, что выделение биологического разнообразия или экосистем в качестве объекта экологических правоотношений вполне оправдано. Для отграничения экологических от иных объектов правоотношений необходимо использовать критерий нахождения конкретного объекта в состоянии взаимодействия с природной средой.

Следовательно, животные, находящиеся в зоопарке или цирке (а равно земля в цветном горшочке, вода в водопроводе и др.) не могут являться объектами экологических правоотношений. Эти отношения регулируются нормами других отраслей права (главным образом, гражданского права). Относительно же обоснованности отнесения дендрологических парков и ботанических садов к категории ООПТ следует заметить, что этот вопрос не имеет однозначного ответа. С одной стороны, данные коллекции растений носят искусственный характер и высажены человеком. С другой стороны, такие территории выполняют важные экосистемные функции и заслуживают особой охраны.

Отдельный вопрос состоит в том, являются ли объектом экологических правоотношений бродячие животные (кошки, собаки), которые, с одной стороны, являются домашними животными, а с другой - выпадают из системы гражданских правоотношений. Такие животные находятся в состоянии естественной свободы и часто склонны к одичанию, в результате чего окончательно утрачивают свойства объекта гражданских прав. Представляется, что такие животные занимают особое место в системе объектов правоотношений, образуя отдельную группу, а их правовой режим определяется нормами экологического, административного, муниципального и гражданского права.
Кроме того, стоит заметить, что развитие научных технологий уже ставит на повестку дня вопрос о том, следует ли рассматривать в качестве экологических отношения в сфере производства генетически модифицированных продуктов или продукции, полученной с использованием нанотехнологий.

Не меньшие дискуссии вызывают следующие вопросы, связанные с дальнейшим развитием категории «объект экологического правоотношения»:

1. В научной литературе отмечается, что преобразовательная деятельность современного человека влечет появление самых разных искусственных природных объектов. Кроме уже упомянутых дендрологических парков и ботанических садов, в результате строительной деятельности постоянно создаются искусственные земельные участки, каналы, водохранилища, пруды, а также обводненные карьеры. Российский законодатель признает их природными объектами, используя фикцию искусственного уподобления и приравнивания (распространения правового режима). Это обстоятельство обусловило появление весьма перспективного предложения о том, чтобы в системе природных объектов (как объектов правоотношений) выделить названные объекты (искусственно созданные) в отдельную подгруппу и обозначить их как «квазиприродные» объекты, имеющие реально существующие экологические связи с окружающей средой [6, с. 15]. Действительно, ряд объектов, хотя и признаются природными, не имеют естественного происхождения, обладая двойным статусом (природный объект и объект недвижимости).

В целом поддерживая данное предложение, следует все же заметить, что не совсем ясны критерии, отграничивающие данную новую правовую конструкцию от смежных категорий. Например, в ходе мелиорации происходит строительство мелиоративных систем (которые могут обладать признаками недвижимости) в целях улучшения качества земельных участков сельскохозяйственного назначения. Кроме того, в силу п. 4 ст. 13 ЗК РФ при проведении связанных с нарушением почвенного слоя строительных работ и работ по добыче полезных ископаемых плодородный слой почвы снимается и используется для улучше- 
ния малопродуктивных земель. Отсюда возникает следующий вопрос: влечет ли мелиорация перемещение почвы, появление «квазиприродного объекта», или же это иная правовая реальность? Можно ли сказать, что правовая конструкция «квазиприродный объект» распространяется только на водохранилища, пруды и искусственные земельные участки? Эти вопросы требуют дальнейшего исследования и проработки.

Столь же интересным является и предложение К.А. Селивановой о выделении нового объекта экологических правоотношений - «аграрной экосистемы», под которой понимается «искусственно созданная или измененная человеком экосистема, имеющая пространственно-территориальные границы, в которой природные и природно-антропогенные объекты взаимодействуют между собой как единое функциональное целое, связаны обменом веществ, энергией и воздействием человека, с целью повышения продуктивности сельскохозяйственного производства» $[18$, c. 9]. Поддерживая в целом такое предложение (являющееся дальнейшим развитием классификации объектов экологических правоотношений на естественные, модифицированные и трансформированные, предложенной еще В.В. Петровым [14, с. 100]), представляется необходимым четко определиться в вопросе о том, является ли аграрная экосистема природным, природно-антропогенным или антропогенным объектом.

2. В последние годы в эколого-правовой науке развернулась дискуссия о том, является ли человек объектом экологических правоотношений. Сторонники данной концепции считают, что человек - это часть природы [7, с. 163; 10, c. 29], а не только субъект правоотношений, и такое включение человека в перечень объектов охраны окружающей среды не противоречит сущности экологического законодательства $[16$, с. 83-87]. Они пишут, что человек - это биологическое существо, также, как и человечество - «это часть природы, и как бы они по своему уровню развития качественно не выделялись среди других ее форм, их существование возможно лишь внутри природной среды и на основании ее звеньев» [20, с. 5].

Противники данной концепции указывают на тот факт, что если человек - часть природы, то ему право не нужно, в том числе и экологическое право. Природа живет не по праву. В природе все происходит по объективным законам материального мира. «Между тем, объясняя юридическое понятие природы и характеризуя экологическое право в целом, необходимо подчеркнуть, что человек, благодаря присущим ему способностям мыслить и производительно трудиться, выделился из природной среды и образовал общество. Он научился разумно управлять своим поведением, в связи с чем человеку необходимы знания законов природы, закономерностей взаимодействия общества и природы и основанные на этих знаниях социальные инструменты, в частности право, для управления развитием общества в гармонии с природой» [11, с. 34].

Аналогичным образом, другие авторы считают, что человек и гражданин России, «вопреки теории отдельных ученых, никак не может быть объектом экологических отношений. В противном случае человек автоматически становится объектом и в природоресурсных правоотношениях, если продолжать объяснять в учебниках для юристов, что экологическое право есть комплексная отрасль права, объединяющая два противоречивых интереса» $[12$, с. 60$]$.

Утверждение, что человек является «объектом» права, «идет вразрез с гуманистической концепцией права и уравнивает человеческую личность, творческому потенциалу которой обязано своим существованием, в том числе, и право как достижение мировой культуры, с явлениями иного порядка, лишенными созидательной силы» [19, c. 109-159]. В связи с этим, с одной стороны, человека нельзя рассматривать в качестве объекта экологического права, поскольку, даже являясь своеобразной «частью природы», он сильно отличается от любых других объектов правоотношений. На это обращал внимание Н.Н. Вопленко, отмечавший, что «современное цивилизованное государство не может и не должно рассматривать человеческую личность в качестве объекта правовых отношений, ибо это ведет к ее ограничению в гражданских правах, превращает в товар, объект купли-продажи и т. д.» $[9$, с. 622]. С другой стороны, человек как 
биологический вид объективно является частью природы, и, как и другие биологические виды, страдает от загрязнения окружающей среды. Соответственно, невозможно охранять окружающую среду только в интересах человека, без учета интересов других живых существ. В связи с этим, исходя из современного состояния правовой системы России, человек не является объектом экологических правоотношений. В то же время в случае дальнейшего развития комплексного подхода к целям и задачам экологического законодательства, ухода от акцента только на интересы человека произойдет трансформация категории «объект правоотношений» с включением в нее человека, что позволит учесть и интересы всех остальных живых организмов.

3. В настоящий момент глобальные изменения климата ставят перед человечеством две основные стратегии выживания: адаптации к изменениям климата и смягчения таких последствий. «Зарубежные эксперты определяют “смягчение" как антропогенное вмешательство, направленное на уменьшение источников или сокращение выбросов парниковых газов» [1, с. 85-91]. Напротив, «адаптация» является «регулятором естественных или человеческих систем в ответ на фактические или ожидаемые климатические изменения или их эффекты, которые смягчают вред или предоставляют новые выгодные возможности. Меры по смягчению последствий изменения климата часто являются превентивными, поскольку обращаются к источникам изменения климата, тогда как адаптация создана как мера реагирования на эффекты уже изменившегося климата» $[27$, с. 6$]$.

При этом если климат как объект экологических правоотношений в той или иной форме указывается в экологическом законодательстве ряда зарубежных стран (например, в ст. 57 Закона Республики Беларусь «Об охране окружающей среды»), то в Российской Федерации мы встретим упоминание о нем только в ряде подзаконных актов (направленных на реализацию международных обязательств России), но не в основных актах экологического законодательства, что, несомненно, требует корректировки.

\section{Заключение}

Таким образом, понимание экологического правоотношения различается в рамках широкого и узкого подходов к предмету экологического права. В рамках узкого подхода наибольшие дискуссии вызывают категории «субъект» и «объект» экологического правоотношения. Представляется обоснованным появление нового субъекта экологических правоотношений - «будущих поколений», упоминаемых в законодательстве. В настоящий момент уже высказан ряд предложений и по расширению традиционного перечня объектов экологических правоотношений, с добавлением в него квазиприродных объектов, аграрной экосистемы, климата и многих других. Данные предложения получили различную оценку в научной литературе. Думается, что безусловной поддержки заслуживает включение в состав объектов экологических правоотношений климата, как это уже было сделано в ряде республик бывшего СССР.

\section{СПИСОК ЛИТЕРАТУРЫ}

1. Анисимов, А. П. Климат как объект экологических правоотношений / А. П. Анисимов // Аграрное и земельное право. - 2015. - № 8. - С. 85-91.

2. Анисимов, А. П. Экологическое право как отрасль права и его место в системе права России: дискуссионные вопросы / А. П. Анисимов // Аграрное и земельное право. - 2016. - № 7. - С. 91-97.

3. Бекишева, С. Д. Экологическое право Республики Казахстан : учеб. пособие / С. Д. Бекишева. - Караганда : Арко, 2009. - 472 c.

4. Боголюбов, С. А. Экологическое право : учебник / С. А. Боголюбов, О. Л. Дубовик. - М. : ТК Велби, Проспект, 2003. - 584 с.

5. Боголюбов, С. А. Сочетание правовых международных и национальных терминов и принципов в экологической сфере / С. А. Боголюбов // Международно-правовое и национальное регулирование экологической сферы общества : сб. ст. - М. : Институт законодательства и сравнительного правоведения при Правительстве РФ, 2011. - C. 35-59.

6. Болтанова, Е. С. Эколого-правовые основы регулирования застройки земель зданиями и сооружениями в России : дис. ... д-ра юрид. наук / Болтанова Елена Сергеевна. - Томск, 2014. - 457 с. 
7. Бринчук, М. М. Экологическое право (Право окружающей среды) / М. М. Бринчук. - М. : Юристь, 1998. - 688 с.

8. Венедиктов, А. В. Правовая природа государственных предприятий. Избранные труды по гражданскому праву. В 2 т. Т. 1 / А. В. Венедиктов. М. : Статут, 2004. - 463 c.

9. Вопленко, Н. Н. Очерки общей теории права / Н. Н. Вопленко. - Волгоград : Изд-во ВолГУ, 2009. $-898 \mathrm{c}$.

10. Дубовик, О. Л. Экологическое право : учебник / О. Л. Дубовик, Л. Кремер, Г. Люббе-Вольфф. М. : Эксмо, 2005. - 768 с.

11. Колбасов, О. С. Терминологические блуждания в экологии / О. С. Колбасов // Государство и право. - 1999. - № 10. - С. 27-37.

12. Максимова, Е. А. Право в социальной структуре обеспечения экологической и природоресурсной безопасности населения в Российской Федерации / Е. А. Максимова, Н. Т. Разгельдеев // Правовые институты и методы охраны окружающей среды в России, странах СНГ и Европейского союза: состояние и эффективность : материалы III Междунар. науч.-практ. конф. преподавателей, практических сотрудников, студентов, магистрантов, аспирантов, соискателей : сб. науч. ст. Саратов : Саратовский источник, 2017. - С. 58-61.

13. Мирошниченко, А. И. Правовой механизм защиты экологического интереса: теоретико-правовой анализ : автореф. дис. ... канд. юрид. наук / Мирошниченко Александр Игоревич. - Краснодар, 2011. $-28 \mathrm{c}$.

14. Петров, В. В. Экологическое право России : учебник для вузов / В. В. Петров. - М. : БЕК, 1995. $557 \mathrm{c}$.

15. Послание Президента Федеральному Собранию. 20 февраля 2019 года. - Электрон. текстовые дан. - Режим доступа: http://kremlin.ru/events/ president/news/59863 (дата обращения: 20.10.2020). Загл. с экрана.

16. Пуряева, А. Ю. Человек в системе объектов охраны окружающей среды / А. Ю. Пуряева // Журнал российского права. - 2007. - № 5. C. $83-87$.

17. Саркисов, О. Р. Экологическое право : учеб. пособие / О. Р. Саркисов, Е. Л. Любарский. - Казань : Центр инновационных технологий, 2014. $335 \mathrm{c}$.

18. Селиванова, К. А. Эколого-правовой механизм в аграрном секторе экономики: направления реализации : дис. ... канд. юрид. наук / Селиванова Ксения Алексеевна. - Оренбург, 2016. - 192 с.

19. Сенчищев, В. И. Объект гражданского правоотношения / В. И. Сенчищев // Актуальные проблемы гражданского права / под ред. М. И. Брагинского. - М. : Статут, 1999. - С. 109-159.
20. Соломина, С. Н. Взаимодействие общества и природы: философские проблемы / С. Н. Соломина. - М. : Мысль, 1983. - 252 с.

21. Теория государства и права : курс лекций / под ред. Н. И. Матузова, А. В. Малько. - М. : Юристь, 1997. - 672 с.

22. Федор, А. И. Экологическое право : учеб. пособие / А. И. Федор. - Волгоград : Волгоградский государственный аграрный университет, 2015. $120 \mathrm{c}$.

23. Чаркин, С. А. Земельные правоотношения как межотраслевая правовая категория : монография / С. А. Чаркин. - М. : Юрайт, 2012. - 237 с.

24. Челышев, М. Ю. Система межотраслевых связей гражданского права: цивилистическое исследование : автореф. дис. ... Д-ра юрид. наук / Челышев Михаил Юрьевич. - Казань, 2009. - 42 с.

25. Экологическое право : пособие / С. А. Балашенко [и др.]. - Минск : Изд-во БелГУ, 2013. - 240 с.

26. Anisimova, A. V. Objects of Environmental Legal Relations: Modern Approaches / A. V. Anisimova // Teoрія і практикаправознавства. -2014.-Вып. 1(5).-С. 14.

27. Parker-Flynn, J. E. The Intersection of Mitigation and Adaptation in Climate Law and Policy / J. E. Parker-Flynn. - Davis : University of California, Davis, 2014. - Vol. 38. - P. 1-47.

\section{REFERENCES}

1. Anisimov A.P. Klimat kak obyekt jekologicheskih pravootnoshenij [Climate as an Object of Ecological Legal Relations]. Agrarnoe i zemel 'noe pravo [Agrarian and Land Law], 2015, no. 8, pp. 85-91.

2. Anisimov A.P. Jekologicheskoe pravo kak otrasl' prava i ego mesto v sisteme prava Rossii: diskussionnye voprosy [Environmental Law as a Branch of Law and Its Place in the System of Law of Russia: Debatable Issues] Agrarnoe i zemel 'noe pravo [Agrarian and Land Law], 2016, no. 7, pp. 91-97.

3. Bekisheva S.D. Jekologicheskoe pravo Respubliki Kazahstan: uchebnoe posobie [Environmental Law of the Republic ofKazakhstan: Study Guide]. Karaganda, Arko Publ., 2009.472 p.

4. Bogolyubov S.A., Dubovik O.L. Jekologicheskoe pravo: uchebnik [Environmental Law: Textbook]. Moscow, TK Welby, Prospect Publ., 2003. 584 p.

5. Bogolyubov S.A. Sochetanie pravovyh mezhdunarodnyh i nacional'nyh terminov i principov v jekologicheskoj sfere [Combination of International and National Legal Terms and Principles in the Environmental Sphere] Mezhdunarodno-pravovoe $i$ nacional 'noe regulirovanie e "kologicheskoj sfery" obshhestva: sbornik statej [International Legal and National Regulation of the Environmental Sphere of 
Society: Collection of Articles]. Moscow, Institute of Legislation and Comparative Law Under the Government of the Russian Federation, 2011, pp. 35-59.

6. Boltanova E.S. Jekologo-pravovye osnovy regulirovanija zastrojki zemel' zdanijami $i$ sooruzhenijami v Rossii [Ecological and Legal Bases of Regulation of Land Construction by Buildings and Constructions in Russia: Dissertation of Doctor of Law]. Tomsk, 2014. 457 p.

7. Brinchuk M.M. Jekologicheskoe pravo (Pravookruzhajushhej sredy) [Environmental Law (Environmental Law)]. Moscow, Jurist Publ., 1998. 688 p.

8. Venediktov A.B. Pravovaja priroda gosudarstvennyh predprijatij. Izbrannye trudy po grazhdanskomu pravu. V 2 t. T. 1 [Legal Nature of State Enterprises. Selected Works on Civil Law. In 2 vols. Vol. 1.]. Moscow, Statut Publ., 2004. 463 p.

9. Voplenko N.N. Ocherki obshhej teorii prava [Essays of the General Theory of Law]. Volgograd, Publishing house of Volgograd State University, 2009. $898 \mathrm{p}$.

10. Dubovik O.L., Kremer L., Lubbe-Wolff G. Jekologicheskoe pravo: uchebnik [Environmental Law: A Textbook]. Moscow, Eksmo Publ., 2005. 768 p.

11. Kolbasov O.S. Terminologicheskie bluzhdanija $\mathrm{v}$ jekologii [Terminology Wanderings in the Ecology]. Gosudarstvo i pravo [State and Law], 1999, no. 10, pp. 27-37.

12. Maksimova E.A., Razgeldeev N.T. Pravo v social'noj strukture obespechenija jekologicheskoj i prirodoresursnoj bezopasnosti naselenija $\mathrm{v}$ Rossijskoj Federacii [Law in the Social Structure of Environmental and Natural Resource Security of the Population in the Russian Federation]. Pravovy'e instituty 'i metody' oxrany 'okruzhayushhej sredy" $v$ Rossii, stranax SNG i Evropejskogo soyuza: sostoyanie $i$ e'ffektivnost': materialy' III Mezhdunarodnoj nauchno-prakticheskoj konferencii prepodavatelej, prakticheskix sotrudnikov, studentov, magistrantov, aspirantov, soiskatelej. Sbornik nauchny'x statej [Legal Institutions and Methods of Environmental Protection in Russia, CIS Countries and the European Union: Status and Effectiveness: Materials of the III International Scientific and Practical Conference of Teachers, Practitioners, Students, Undergraduates, Graduate Students, Applicants. Collection of Scientific Articles]. Saratov, Saratov source Publ., 2017, pp. 58-61.

13. Miroshnichenko A.I. Pravovoj mehanizm zashchity jekologicheskogo interesa: teoretikopravovoj analiz [Legal Mechanism of Protection of Ecological Interest: Theoretical and Legal Analysis: Abstract of the Dissertation of the Candidate of Legal Sciences]. Krasnodar, 2011.28 p.

14. Petrov V.V. Jekologicheskoe pravo Rossii: uchebnik dlja vuzov [Environmental Law of Russia:
Textbook for Universities]. Moscow, BEK Publ., 1995. $557 \mathrm{p}$.

15. Poslanie Prezidenta Federalnomu Sobraniiu. 20 fevralya 2019 goda [Prasident's Message to the Federal Assembly on February 20, 2019]. URL: http://kremlin.ru/events/president/news/ 59863 (accessed 20 October 2020).

16. Puryaeva A.Yu. Chelovek v sisteme obyektov ohrany okruzhajushchej sredy [Man in the System of Objects of Environmental Protection]. Zhurnal rossijskogo prava [Journal of Russian Law], 2007, no. 5, pp. 83-87.

17. Sarkisov O.R., Lubarsky E.L. Jekologicheskoe pravo: uchebnoe posobie [Environmental Law: Training for the Expedient]. Kazan, Center for Innovative Technologies, 2014. 335 p.

18. Selivanova K.A. Jekologo-pravovoj mehanizm $v$ agrarnom sektore jekonomiki: napravlenija realizacii [Ecological and Legal Mechanism in the Agricultural Sector of the Economy: Directions of Implementation: Dissertation of the Candidate of Legal Sciences]. Orenburg, 2016. 192 p.

19. Senchishev V.I. Obyekt grazhdanskogo pravootnoshenija [Object of Civil Legal Relationship]. M.I. Braginsky, ed. Aktual 'ny'e problemy' grazhdanskogo prava [Actual Problems of Civil Law]. Moscow, Statut Publ., 1999, pp. 109-159.

20. Solomina S.N. Vzaimodejstvie obshhestva $i$ prirody: filosofskie problemy [The Interaction of Society and Nature: Philosophical Problem]. Moscow, Mysl' Publ., 1983. 252 p.

21. Matuzov N I., Malko A.V., eds. Teorija gosudarstva i prava: kurs lekcij [Theory of State and Law: A Course of Lectures]. Moscow, Jurist Publ., 1997. $672 \mathrm{p}$.

22. Fedor A.I. Jekologicheskoe pravo: uchebnoe posobie [Environmental Law: A Textbook]. Volgograd, Volgograd State Agrarian University, 2015. 120 p.

23. Charkin S.A. Zemel'nye pravootnoshenija kak mezhotraslevaja pravovaja kategorija [Land Relations as a Cross-Cutting Right Category. A Monograph]. Moscow, Yurayt Publ., 2012. 237 p.

24. Chelyshev M.Yu. Sistema mezhotraslevyh svjazej grazhdanskogo prava: civilisticheskoe issledovanie [System of Intersectoral Relations of Civil Law: Civil Research: Abstract of the Dissertation of Doctor of Law]. Kazan, 2009. 42 p.

25. Balashenko S.A., et al. Jekologicheskoe pravo: posobie [Environmental Law: Manual]. Minsk, Publishing House of the Belarusian State University, 2013. 240 p.

26. Anisimova A.V. Objects of Environmental Legal Relations: Modern Approaches. Theory and Practice of Legal Cognition, 2014, vol. 1 (5), p. 14.

27. Parker-Flynn J.E. The Intersection of Mitigation and Adaptation in Climate Law and Policy. Davis, University of California, 2014, vol. 38, pp. 1-47. 


\section{Information About the Author}

Anatoly Ya. Ryzhenkov, Doctor of Sciences (Jurisprudence), Professor, Department of Civil Law and Procedure, B.B. Gorodovikov Kalmyk State University, A.S. Pushkina St, 11, Bld. 1A, 358000 Elista, Russian Federation, 4077778@list.ru, https://orcid.org/0000-0002-2015-1709

\section{Информация об авторе}

Анатолий Яковлевич Рыженков, доктор юридических наук, профессор кафедры гражданского права и процесса, Калмыцкий государственный университет им. Б.Б. Городовикова, ул. А.С. Пушкина, 11, корп. 1А, 358000 г. Элиста, Российская Федерация, 4077778@list.ru, https://orcid.org/0000-0002-2015-1709 